\title{
Parametric retrieval model for estimating aerosol size distribution via the AERONET, LAGOS station
}

\author{
Moses Eterigho Emetere ${ }^{a,}{ }^{*}$, Marvel Lola Akinyemi ${ }^{a}$, Omololu Akin-Ojo ${ }^{b}$ \\ a Department of Physics, Covenant University Canaan Land, P.M.B 1023, Ota, 122333, Nigeria \\ ${ }^{\mathrm{b}}$ Department of Physics, University of Ibadan, Nigeria
}

\section{A R T I C L E I N F O}

Article history:

Received 26 June 2015

Received in revised form

18 September 2015

Accepted 21 September 2015

Available online 2 November 2015

\section{Keywords:}

Aerosol size distribution

Optical bands

Aerosol optical depth

Unified number

Dispersion model

\begin{abstract}
A B S T R A C T
The size characteristics of atmospheric aerosol over the tropical region of Lagos, Southern Nigeria were investigated using two years of continuous spectral aerosol optical depth measurements via the AERONET station for four major bands i.e. blue, green, red and infrared. Lagos lies within the latitude of $6.465^{\circ} \mathrm{N}$ and longitude of $3.406^{\circ} \mathrm{E}$. Few systems of dispersion model was derived upon specified conditions to solve challenges on aerosols size distribution within the Stokes regime. The dispersion model was adopted to derive an aerosol size distribution (ASD) model which is in perfect agreement with existing model. The parametric nature of the formulated ASD model shows the independence of each band to determine the ASD over an area. The turbulence flow of particulates over the area was analyzed using the unified number (Un). A comparative study via the aid of the Davis automatic weather station was carried out on the Reynolds number, Knudsen number and the Unified number. The Reynolds and Unified number were more accurate to describe the atmospheric fields of the location. The aerosols loading trend in January to March (JFM) and August to October (ASO) shows a yearly $15 \%$ retention of aerosols in the atmosphere. The effect of the yearly aerosol retention can be seen to partly influence the aerosol loadings between October and February.
\end{abstract}

(c) 2015 Elsevier Ltd. All rights reserved.

\section{Introduction}

Biomasses burning are common activity between October to February (the dry season) which engender from wild, wood, dung, domestic, industrial and agricultural fires. However, the alarming increase of wildfire aerosol in Africa is traceable to about $70 \%$ of the total area burned worldwide annually (Giglio et al., 2010). The summation of biomass burning and other aerosol plume sources (Emetere Moses, 2013, 2014; Emetere Moses and Akinyemi, 2013; Omotosho et al., 2015) indeed affect the climate system of the area. The vertical and horizontal transport patterns of the plume lead to several physical and chemical protocols in the atmosphere. For example, it was recently reported of secondary aerosol formation via biomass burning plumes in South Africa (Vakkari et al., 2014). Hence, the continuous aerosol loadings in the atmosphere lead to a complex comprehension of regional circulation and seasonal pollutant variation. Scientists have made several attempts to evaluate the mechanism of seasonal pollutant variation e.g. the sun

\footnotetext{
* Corresponding author.

E-mail address: moses.emetere@covenantuniversity.edu.ng (M.E. Emetere).
}

photometers was used to study column optical properties (He et al., 2012); lidar systems to examine vertical profiles of atmospheric aerosols at high temporal and spatial resolution (Liu et al., 2011); EARLINET to determine the bottom and top layer heights of the aerosols in free troposphere (Sicard et al., 2015); and satellite imagery to investigate the optical, chemical and microphysical characterization of aerosol particles (Hussein et al., 2004). However, the behavior of pollutants varies with respect to the contraction and expansion of both the frictionless and friction atmospheric layers. For example, frictionless or free tropospheric aerosols originate from long-range transport while tropospheric aerosols in the frictional layer (planetary boundary layer) originate from local sources and regionally transported aerosols. The regional aerosols transport within the PBL is majorly influenced by marine air masses and the long-range transport of desert dust (Rajeev et al., 2000). Hence, the collective role of regional, localized and remote aerosol transport over an area makes it difficult to accurately determine the type of aerosol distribution or aerosol distribution size over an area per time. Wang et al. (2015) examined the relationship between AOD and some parameters like aerosol size distribution, refractive index and scattering albedo. The statistical analysis conducted by Wang 
et al. (2015) revealed that the highest average values of the parameters could be attained at wavelength $440-1020 \mathrm{~nm}$. Che et al. (2014) considered the AOD at some specific wavelength (500 nm and $675 \mathrm{~nm}$ ) to determine the direct radiative forcing via its aerosol optical properties in rural, suburban and urban regions. The atmospheric radiative forcing exceeded $-200 \mathrm{Wm}^{-2},-180 \mathrm{Wm}^{-2}$ and $-50 \mathrm{Wm}^{-2}$, at urban, suburban and rural respectively.

The formation of theoretical or mathematical models to explain the physics of the aerosol transport have severally suffered set-back which ranges from the initial or boundary conditions, bogus formulations for turbulent or mild fluid flow, misconceptions about the Stokes' regime, assumptions of the wind analysis. The comprehensive incorporation of all known and unknown factors which creates wide variation between satellite or in-situ measurements and mathematical models can be achieved by adopting a seasonal duration. In this study, each season lasts for a period of three months i.e. December to February (DFJ) which kick-starts summer, March to May (MAM) i.e. autumn, June to August (JJA) i.e. winter and September to November (SON) i.e. spring (Soukharev and Hood, 2006).

The use of aerosol optical depth (AOD) to describe aerosol size distribution has not been faulted because it contains information pertaining to aerosol size distribution, Angstrom exponent -qualitative indicator of aerosol distribution and turbidity coefficientaerosol loading indicator in vertical column (Sharma et al., 2011; Nnaemeka et al., 2015; Emetere Moses et al., 2015). The qualitative indicator with Angstrom exponent values greater than 2 indicates small particles associated with combustion byproducts while values less than 1 indicates large particles like sea salt and dust (Schuster et al., 2006a,b). The aerosol size distribution is multimodal in nature, hence, there exists the possibility of fundamental errors in its basic modeling (Kaskaoutis et al., 2010). Scientists have tried categorizing multi-modal challenges via the Angstrom exponent $(\alpha)$. For example, coarse mode aerosols such as dust or sea salt exist when $\alpha \leq 1$ while fine mode aerosols exist when $\alpha \geq 2$ (Schuster et al. 2006a,b). This assumption guides mathematical modeling of aerosol transport when using the Angstrom Power Law given as

$\tau(\lambda)=\beta \lambda^{-\alpha}$

Here, $\tau(\lambda)$ is the AOD, $\alpha$ is the Angstrom exponent, $\beta$ is the turbidity coefficient, $\lambda$ is the wavelength. The polynomial re-order of Eq. (1) has been discussed. Its success is short-lived because it expands the fundamental errors of the protocols (Eck et al., 1999). To address the errors, scientists have proposed that the definition of the various boundary layers would enhance more accurate results e.g. when $\lambda=1064 \mathrm{~nm}$, the analysis of the local maximum via first derivative of backscatter indicates the bottom layer of the boundary layer while a lower $\lambda$ signifies the top of the layer. In other words, values of AOD can be determined by two different wavelengths i.e.

$\alpha=-\frac{\ln \left(\frac{\tau\left(\lambda_{1}\right)}{\tau\left(\lambda_{2}\right)}\right)}{\ln \left(\frac{\lambda_{1}}{\lambda_{2}}\right)}$

The mathematical modeling of AOD through signal of solar radiation explains the physics of the tropospheric particulates as they react to the continuous effects of scattering and absorption. This technique can be used to determine the AOD since aerosol particles interacts with solar radiation in space to influence energy budget. Hence, AOD can be related to solar radiation as

$I=I_{o} \exp (-\tau)$
Here, $I_{0}$ is the solar irradiance at the top of atmosphere, $I$ is the solar irradiance after passing through the atmosphere, $\tau$ is the AOD (Liou, 2002) which is written as

$\tau=\left[\ln I_{o}-\ln I-\left(\tau_{\text {Ray }} \times m\right) \times\left(\frac{p}{p_{o}}\right)\right] / m$

Here $\tau_{\text {Ray }}$ is the Rayleigh scattering (depends on wavelength), $p_{o}$ is the pressure in standard atmosphere on the sea level, $p$ is the local atmospheric pressure, $m$ is the air mass. The complexity of aerosol in time and space makes it difficult for any mathematical model to capture its behavior at certain altitude. The limited AOD surface observations especially in West Africa led to the use of salient surface meteorological parameter to determine the aerosol distribution (Emetere Moses et al., 2015). This feat was achieved by the reconstruction of the Kumierczyk-Michulec (1993) aerosol optical depth equations i.e.

$\tau_{a}(\lambda)=a\left[\frac{E_{t o t}(\lambda)}{G_{s}(\lambda) \beta^{-1} \cos (\theta) T_{r}(\lambda)}-\frac{\left(1-T_{r}^{b}(\lambda)\right)}{c T_{r}(\lambda)}\right]$

Here $b=0.95, c=2, E_{\text {tot }}(\lambda)$ is the total irradiance, $\lambda$ is the wavelength, $T_{r}(\lambda)$ is the transmittance functions for Rayleigh scattering, $\beta$ is the correction factor for the Earth-Sun distance. $G_{s}(\lambda)$ is the extra-terrestrial index which can be determined by

$G_{S}(\lambda)=\left(\frac{G H}{J}\right)$

$\mathrm{G}$ is the cloud cover index, $\mathrm{H}$ is the relative humidity index, $\mathrm{J}$ is the rainfall index. The constants highlighted in Eq. (5) can be contested based on regional weather peculiarities and global climate change. However, this technique is more appropriate for the free troposphere. Therefore in this paper, we consider a surface observation technique via the plume dispersion model that is expected to incorporate multi dispersion sources e.g. biomass burning. The technique is used to reconstruct the AOD satellite measurement with the primary aim of defining the aerosol size distribution. The two major techniques for analyzing aerosol size distribution have been faulted in one way or the other. The first technique is the approximate sectional technique which works on the principle of size or molecular resolution. This technique was faulted on the expansion features of particulates (Lehtinen and Kulmala, 2003). The second technique is the fixed sectional technique which works via constants attributed to each section. This technique has been proved to be effective in atmospheric dynamic systems (von Salzen et al., 2000). In this paper, the modified fixed sectional technique shall be adopted by introducing dynamic constants which shall be obtained from the unified number that shall be explained in section three.

\section{Theory: the concept of the aerosol dispersion plume model}

Emetere Moses and Akinyemi (2013) propounded the 3D plume model. The model was used to investigate the pollution from cement factory. The model showed excellent correspondence with the pollutant dispersion and depositions around the factory. The governing equation was given as

$$
\begin{aligned}
\frac{\partial C}{\partial t}+V_{x} \frac{\partial C}{\partial x}-V_{z} \frac{\partial C}{\partial z}-V_{y} \frac{\partial C}{\partial y} & =\frac{\partial}{\partial z}\left(K_{z} \frac{\partial C}{\partial z}\right)+\frac{\partial}{\partial y}\left(K_{y} \frac{\partial C}{\partial y}\right) \\
& +\frac{\partial}{\partial z}\left(K_{z 2} \frac{\partial C}{\partial z}\right)+\frac{\partial}{\partial y}\left(K_{y 2} \frac{\partial C}{\partial y}\right)-P+S
\end{aligned}
$$


Here, $V$ is the wind velocity $(\mathrm{m} / \mathrm{s}), \mathrm{P}$ is the air upthrust, $\mathrm{x}$ is the wind coordinate measured in wind direction from the source, $y$ is the cross-wind coordinate direction, $\mathrm{z}$ is the vertical coordinate measured from the ground, $\mathrm{C}(\mathrm{x}, \mathrm{y}, \mathrm{z})$ is the mean concentration of diffusing pollutants of diffusing substance at a point $(x, y, z)\left[\mathrm{kg} / \mathrm{m}^{3}\right]$, $\mathrm{Ky}, \mathrm{Kz}$ is the eddy diffusivities in the direction of the $\mathrm{y}$ - and $\mathrm{z}$-axes $\left[\mathrm{m}^{2} / \mathrm{s}\right], \mathrm{S}$ is the source/sink term $\left[\mathrm{kg} / \mathrm{m}^{3}-\mathrm{s}\right]$. Zhang et al. (2014) adopted Eq. (7) but represented $\lambda c=-P+S$. Where $\lambda$ is the climatic factor and $c$ is contaminant concentration. Climatic factor can be emission source, chemical conversion, dry deposition and wet scavenging. The logarithmic distribution of the wind speed and exponential function form of turbulent diffusivity was incorporated into the refined Eq. (7). However, the turbulent diffusivity with its corresponding wind speed cannot be related by mere assumption and subsequent use of the Kriging interpolation method. Therefore a comprehensive mathematical representation is required to appreciate the corporate influence of the wind direction in the plume.

$V_{z} \frac{\partial C}{\partial z}=\frac{\partial}{\partial z}\left(K_{z} \frac{\partial C}{\partial z}\right)+\frac{\partial}{\partial y}\left(K_{y} \frac{\partial C}{\partial y}\right)+\frac{\partial}{\partial x}\left(K_{z} \frac{\partial C}{\partial x}\right)$

$V_{x} \frac{\partial C}{\partial x}=\frac{\partial}{\partial y}\left(K_{y 2} \frac{\partial C}{\partial y}\right)+\frac{\partial}{\partial z}\left(K_{z 2} \frac{\partial C}{\partial z}\right)+\frac{\partial}{\partial x}\left(K_{z 2} \frac{\partial C}{\partial x}\right)$

Eqs. (8) and (9) represents the turbulent and mild dispersion equation respectively. The mild dispersion equation describes the scenario in the free troposphere while the turbulent dispersion equation describes what happens below the planetary boundary layer. In the parametric study, both equations occur in two 2D on the account of individual gas molecule transport. The ascending particulate-mild dispersion is mathematically expressed as

$$
\left.\begin{array}{c}
V_{x} \frac{\partial C_{1}}{\partial x}=\frac{\partial}{\partial y}\left(K_{y 2} \frac{\partial C}{\partial y}\right)+\frac{\partial}{\partial z}\left(K_{z 2} \frac{\partial C}{\partial z}\right) \\
V_{x} \frac{\partial C_{2}}{\partial x}=\frac{\partial}{\partial z}\left(K_{z 2} \frac{\partial C}{\partial z}\right)+\frac{\partial}{\partial x}\left(K_{z 2} \frac{\partial C}{\partial x}\right)
\end{array}\right\}
$$

while the descending particulate-mild dispersion is mathematically expressed as

$$
\left.\begin{array}{r}
V_{x} \frac{\partial C_{1}}{\partial \mathrm{x}}=\frac{\partial}{\partial y}\left(K_{y 2} \frac{\partial C}{\partial y}\right)-\frac{\partial}{\partial z}\left(K_{z 2} \frac{\partial C}{\partial z}\right) \\
V_{x} \frac{\partial C_{2}}{\partial x}=-\frac{\partial}{\partial z}\left(K_{z 2} \frac{\partial C}{\partial z}\right)+\frac{\partial}{\partial x}\left(K_{z 2} \frac{\partial C}{\partial x}\right)
\end{array}\right\}
$$

for a trivial case, Eq. (10) can be solved-using separation of variable i.e. $C=X(x) Y(y)$ with the initial boundary conditions as $\mathrm{X}=1, \mathrm{X}=1$; $\mathrm{y}=1, \mathrm{Y}=1 ; \mathrm{z}=1, \mathrm{Z}=1$. The solution is given as

$$
C(x, y, z)=a^{2} \mathrm{bcos}\left(\frac{\mathrm{n}}{\mathrm{k}_{\mathrm{y}}}+\alpha\right) \cos \left(\frac{\mathrm{n}}{\mathrm{k}_{\mathrm{z}}}+\beta\right) \exp \left(\frac{n^{2}}{V_{x}}\right)
$$

$a, b, n, \alpha$, and $\beta$ are constants that would be determined via remotely sensed data set. Omotosho et al. (2015) used Eq. (12) to derive the constants of gas flares in Niger Delta region of Nigeria. From the above equation, $a^{2} \mathrm{~b}$ is known as the tuning constants, $\alpha$ and $\beta$ is multiplier constant, $n$ is decay/growth constant. For easy representation, we refer the tuning, growth/decay and multiplier constants as atmospheric constants. The success of Eq. (12) was the generation of atmospheric constants at some region of Niger Delta (Schotland and Lea, 1986; Welton et al., 2002; Omotosho et al., 2015) which corresponds with the atmospheric constant obtained at the Atmospheric Centre, Macehead (when the Canadian general climate model is used).

In a detailed scenario, we propose that the ascending particulate-mild dispersion applies to atmospheric aerosols. This means other processes like nucleation e.t.c. should act on Eq. (10) to capture either the primary or secondary aerosol formation within an area. Aloyan et al., (2012) had described the change of concentrations of aerosol components for both advective transport (Eq. (13)) and turbulent mixing (Eq. (14)) as

$$
\begin{aligned}
& \frac{\partial C_{i}}{\partial t}+V_{j} \frac{\partial C_{i}}{\partial x_{j}}=F_{i}^{g a s}-P_{i}^{n u c l}-P_{i}^{c o n d}+P_{i}^{c H e m}+\frac{\partial}{\partial x_{j}}\left(K_{j j} \frac{\partial C_{i}}{\partial x_{j}}\right) \\
& \frac{\partial \psi_{k}}{\partial t}+\left(V_{j}-\delta_{j 3} w_{g}\right) \frac{\partial \psi_{k}}{\partial x_{j}}=F_{k}^{a e r}+P_{k}^{n u c l}+P_{k}^{c o n d}+P_{k}^{c o a g}+\frac{\partial}{\partial x_{j}}\left(K_{j j} \frac{\partial \psi_{k}}{\partial x_{j}}\right)
\end{aligned}
$$

where $\left(x_{1}=x, x_{2}=y, x_{3}=z\right),\left(u_{1}=u, u_{2}=v, u_{3}=w\right) ;(j=1,2,3) ; C i$ $\left(i=1, \ldots, N_{g}\right)$ and $\psi_{k}\left(k=1, \ldots, N_{a}\right)$ are the concentrations of gaseous admixtures and aerosols, respectively; $N_{g}$ and $N_{a}$ are the numbers of the corresponding components; $w_{g}$ is the is the gravitational settling; $F^{g a s}$ and $F^{a e r}$ are the emissions of gaseous admixtures and aerosols, respectively; $P^{\text {nucl }}, P^{\text {cond }}, P^{\text {coag }}, P^{\text {chem }}$ are the operators of nucleation, condensation, coagulation, and photochemical transformation, respectively; $k_{j j}$ is the turbulent diffusion coefficient along $\mathrm{x}, \mathrm{y}, z$ coordinates, respectively. The physics of the turbulent advective transport of aerosol in the troposphere would be the combination of Eqs. (13) and (14) when $F^{g a s}=F^{a e r}$.\& $\psi_{k}=C_{i}$, $P^{\text {chem }}=P^{\text {coag }}$. Hence, the incorporation of Eq. (10) into the summation results of Eqs. (13) and (14) is given as

$$
\begin{gathered}
\frac{\partial \psi_{k}}{\partial t}+\frac{\partial}{\partial y_{j}}\left(K_{j j} \frac{\partial \psi_{k}}{\partial y_{j}}\right)+\frac{\partial}{\partial z_{j}}\left(K_{j j} \frac{\partial \psi_{k}}{\partial z_{j}}\right)-\left(\frac{\partial}{\partial x_{j}}\left(K_{j j} \frac{\partial \psi_{k}}{\partial x_{j}}\right)\right. \\
\left.+\frac{1}{2} \delta_{j 3} w_{g} \frac{\partial \psi_{k}}{\partial x_{j}}\right)=F_{k}^{a e r}+P_{k}^{c o a g}
\end{gathered}
$$

or

$$
\frac{\partial \psi_{k}}{\partial t}+\frac{\partial}{\partial z_{j}}\left(K_{j j} \frac{\partial \psi_{k}}{\partial z_{j}}\right)-\frac{1}{2} \delta_{j 3} w_{g} \frac{\partial \psi_{k}}{\partial x_{j}}=F_{k}^{a e r}+P_{k}^{c o a g}
$$

The viability of $P_{k}^{\text {coag }}$ in the above equation is difficult because coagulation lowers the concentration of atmospheric particles and may be very tasking obtaining via numerical model (Lohmann et al., 2000). Therefore it is assumed that the effect of particle collisions on the size distribution is negligible, hence, $P_{k}^{\text {coag }}=0$. The numerical diffusion of the equation can be eliminated by introducing the condensational effects of aerosol emission $F_{k}^{a e r}$. Hence

$F_{k}^{a e r} \approx \frac{\partial m_{k}}{\partial t}=D_{k} m-\frac{1}{3} \frac{\partial D m_{k}}{\partial \mu}$

where $m_{k}$ is the mass distribution, D is its mass transfer rate, and $\mu$ is the logarithm of particle diameter. If the particle diameter is assumed to be uniform, then $1 / 3 \partial D m_{k} / \partial \mu \rightarrow 0$. Hence we propose that

$\tau=\frac{1}{D_{k}} F_{k}^{a e r} \approx \frac{1}{D_{k}} \frac{\partial m_{k}}{\partial t}$

Hence, Eq. (16) transforms to

$\frac{\partial \psi_{k}}{\partial t}+\frac{\partial}{\partial z_{j}}\left(K_{j j} \frac{\partial \psi_{k}}{\partial z_{j}}\right)-\frac{1}{2} \delta_{j 3} w_{g} \frac{\partial \psi_{k}}{\partial x_{j}}=\tau D_{k}$ 
Eq. (17) describes both the optical and physical properties of the aerosols. Therefore, its application to solve live problems requires the adequate definition of the initial and boundary conditions. Initial and boundary conditions of pollutants are very important either in forecast or on the spot analysis. If the Initial and boundary conditions are based on large-scale simulation or climatic average values, the output of the forecast or analysis would be error-prone (Wang et al., 2014). We adopted the initial and boundary conditions for vertical from Wang et al. (2014) and horizontal resolution from the NASA-Unified Weather Research and Forecasting.

\subsection{Dynamics of particulates: the theoretical anomalies}

The beauty of Eq. (19) is its active expression of the Stokes drag which is evident in the Stokes regime or creeping flow regime at small Reynolds numbers ( $\operatorname{Re}<0.5)$. At higher Reynolds numbers, the drag coefficient requires correction i.e. Knudsen number or Cunningham correction factor or both in some cases. The application of the Cunningham correction factor requires that a wide range of the Knudsen number i.e. $K n=\lambda / d_{p} \leq 1000$ at low Reynolds number. How unique is the Stokes' velocity in understanding the dynamism of pollutants or particulates? The gravitational settling $\left(w_{g}\right)$ in Eq. (19) requires the Stokes terminal velocity within the Stokes' regime. It is written as

$v_{g}=\frac{D^{2}\left(\rho_{p}-\rho_{\text {air }}\right) g C_{c}}{18 \mu_{\text {air }}}$

Here, $\mathrm{D}$ is the diameter of particulates, $\rho_{p}$ is its density, $\mu_{\text {air }}$ is the air dynamic viscosity, $g$ is the gravity constant, $\mathrm{Cc}$ is the Cunningham coefficient and $\rho_{\text {air }}$ is the air density. Where $\mathrm{Cc}$ is given as

$C_{c}=1+\frac{2 \lambda}{d_{p}}\left(1.257+0.4 \exp \left(-0.55 \frac{d_{p}}{\lambda}\right)\right)$

Here $\lambda$ denotes the molecular mean free path in the gas. Cunningham correction factor applies to the Stokes law settling velocity for minute particles at standard temperature and pressure. Cunningham correction factor is insignificant when being applied to the atmospheric dispersion problems because the settling velocities of the particles are extremely small compared to vertical motions. In order to achieve the aim of this paper i.e. aerosol distribution size, the correction to the Stokes drag should incorporate adequate estimation of the aerosol size and the vertical motions. To address this major problem, Emetere Moses (2014a,b) came up with the Unified number (Un). The Unified number governs the convective phenomena between two interacting fluids (monodispersion and poly-dispersion flows) that are separated by a conducting medium. It was derived via the Poiseuille's criteria by the inclusion of two salient parameters i.e. unified number $(\mathrm{U})$ and temperature profiles. The basic operation of this model concentrates on the vertical motion along the $z$-axis. $U$ is the unified parameter and it is defined as

$U=\frac{\rho C_{p} U_{a}}{h} \theta$

$U_{a}$ is the mean velocity of that fluid, $C_{p}$ is specific heat at constantpressure, $\rho$ is the density, $h$ is the convective heat transfer coefficient and $\theta$ is the thermal ratio which defines the ratio of the average temperature of fluid in the pipe to the room temperature of the pipe. The unified number has been validated in the laboratory framework (Emetere Moses, 2014a,b). The unified number was used determine the volume flow rate which varies to the third power of the diameter (D), in this regard, the volume flow rate which varies to the third power of the mean path. How related is this unified number to the concept of determining the aerosol size determination? We considered a one year wind data analysis from the Davis automatic weather station in the next chapter.

\section{Validation of the unified number using wind analysis}

The Davis automatic weather station is a weather monitoring equipment - used to monitor atmospheric variables such as pressure, temperature, relative humidity, wind speed, solar radiation and a host of other parameters. The Davis weather station comprises of sensors (which serves as Thermometer, Barometer, Hygrometer, Anemometer, Disdrometer, Transmissometer, Ceilometer, Pyranometer) and a data logger. We set the data logger to capture values every minute. An average volume of about four hundred and eighty thousand $(480,000)$ wind speed data for wind directions-NE, SW, SE, NW, NNW, N, W, ESE, ENE, NNE, E, WSW, WNW, SSW and SSE. The location of study is (Covenant University, Ota South-Nigeria) on latitude $6.7^{\circ} \mathrm{N}$ and longitude $3.23^{\circ} \mathrm{E}$. The data studied were divided into night time $(10 \mathrm{pm}-11 \mathrm{pm})$; afternoon time $(2 \mathrm{pm}-3 \mathrm{pm})$ and morning time (4am-5am). The three extends for only day 17 of each month. In this section, only February is reported to establish the validation of the unified number. By definition, the Reynolds and Unified number are defined on two common parameters i.e. air density and wind speed. The features of air density and wind speed with respect to time are shown in Fig. 1. We monitored the wind speed events within December to February to ascertain its variability as shown in Table 1. From the comprehensive data set obtained from the Davis weather station, it takes $13 \mathrm{~min}$ (maximum) for specific wind pattern (of same direction or speed e.g. NE-4 m/s) to regain its original state within the specified time (night time $(10 \mathrm{pm}-11 \mathrm{pm})$; afternoon time (2pm-3pm) and morning time (4am-5am)). Since, atmospheric ventilation, stagnation and recirculation are air flow conditions that either aid or hinder quick dispersion (Kumar et al., 2013), we examined the fluid dynamics of a 13 min events using the Knudsen, Reynolds and Unified numbers. From literature (Nicholson Sharon, 2013), the peculiarity of the West Africa monsoon informed the choice of February.

In Fig. 1b, the maximum wind speed (within the defined duration) was noticed in the afternoon with a high tendency of instability (Fig. 1a). The lowest speed (within the defined duration) was noticed in the morning with a high tendency of stability (Fig. 1a).

The validity of the unified number on atmospheric field was tested using the range of the ratio $\left(C_{p} / h\right)$ i.e. $0.1,0.3,0.5$ and 0.9 on the afternoon data (Fig. 2a). The direct relationship of $C_{p} / h$ on the proposed results affirmed that its influence on the general result is moderate and can be relied upon for analysis. The general analysis for the morning afternoon and night data (Fig. 2b) shows that the Un results agree with the trending of the primary data i.e. wind speed (Fig. 1b). Also, the results of the Reynolds number at $\mathrm{D}=0.001 \mathrm{~nm}$ is shown in Fig. 3a. This result further affirms the validation of Un for atmospheric fields. The analysis of the Knudsen number $(\mathrm{Kn})$ showed a wide variation as applied to the atmospheric field. Fig. 3b showed the Kn for night. The agreement of the highest peaks for night in Figs. 1a and 3a was noticedshowing that the Kn may be relevant to explain the night flows in the location of study. The Kn feature deviates gradually from morning (Fig. 4a) to afternoon (Fig. 4b). This shows that the Kn becomes more inaccurate to capture the dynamics of the lower atmosphere when the turbulence in the lower atmosphere increases. What effect does this portend to the aerosol size distribution? The analysis of such effect is expressed in the solution of Eq. (19). 

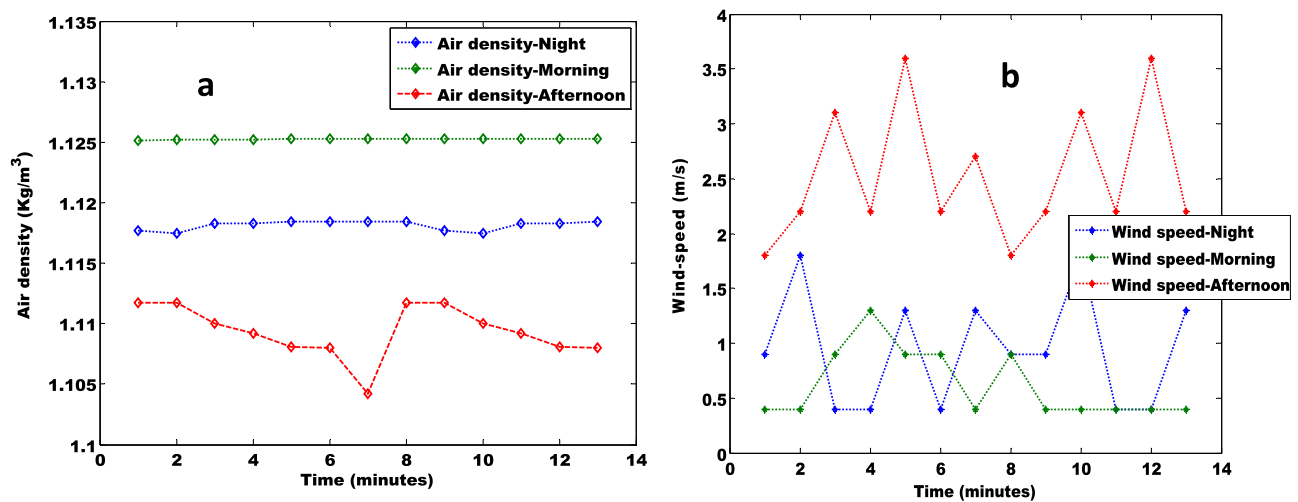

Fig. 1. a: Air density (morning, afternoon and night). b: wind speed (morning, afternoon and night).

Table 1

Data of the wind direction for the DJF.

\begin{tabular}{|c|c|c|c|c|c|c|}
\hline Wind direction & Max. wind speed $(\mathrm{m} / \mathrm{s})$ & Volume of data & Max. wind speed $(\mathrm{m} / \mathrm{s})$ & Volume of data & Max. wind speed $(\mathrm{m} / \mathrm{s})$ & Volume of data \\
\hline & December & & January & & February & \\
\hline SE & 2.2 & 14 & 6.3 & 156 & 5.4 & 128 \\
\hline $\mathrm{S}$ & 4 & 29,131 & 6.3 & 121 & 6.7 & 250 \\
\hline NW & 4.9 & 75 & 6.7 & 2554 & 6.3 & 2421 \\
\hline NNW & 6.7 & 20 & 4.5 & 919 & 3.1 & 531 \\
\hline $\mathrm{NE}$ & 3.6 & 21 & 4.5 & 1168 & 4.0 & 1389 \\
\hline $\mathrm{N}$ & 4 & 1536 & 4 & 1536 & - & - \\
\hline ESE & 4.5 & 85 & 5.8 & 494 & 3.6 & 374 \\
\hline ENE & 4 & 60 & 5.8 & 148 & 4.5 & 3398 \\
\hline NNE & 4.5 & 42 & 4.5 & 721 & 3.6 & 601 \\
\hline E & 4.5 & 530 & 4.5 & 294 & 4.5 & 1681 \\
\hline WSW & 4 & 244 & 7.2 & 3293 & 7.2 & 6391 \\
\hline WNW & 2.7 & 92 & 7.2 & 2284 & 6.7 & 2867 \\
\hline W & 3.6 & 367 & 7.6 & 4908 & 7.6 & 5900 \\
\hline SW & 3.1 & 222 & 5.8 & 700 & 5.8 & 1694 \\
\hline SSW & 2.7 & 63 & 4.5 & 153 & 8.5 & 234 \\
\hline SSE & 2.1 & 44 & 6.7 & 70 & 6.3 & 129 \\
\hline Static & - & 1235 & - & 987 & - & 1121 \\
\hline
\end{tabular}
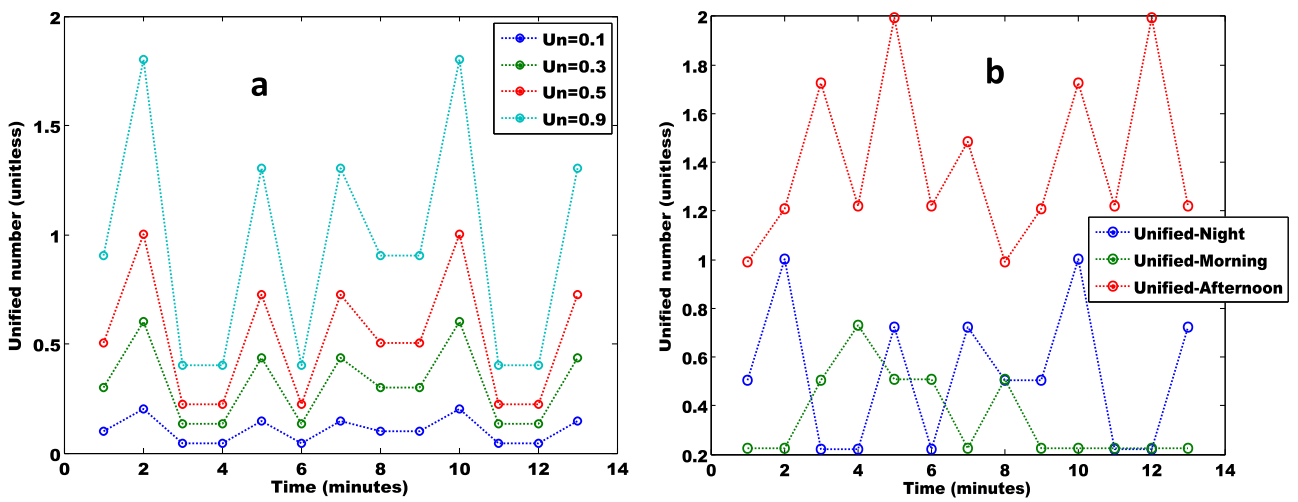

Fig. 2. a: The effect of $C_{p} / h$ on the unified number results. b: Unified number for morning, afternoon and night.

\subsection{Numerical modeling of the aerosol size distribution}

In this section, the aerosol size distribution concept would be investigated in the light of Eq. (19) using the Multi-angle Imaging SpectroRadiometer (MISR). The MISR was launched in 1999 to measure the intensity of solar radiation reflected by the planetary surface and atmosphere. The MISR operates at various directions i.e. nine different angles $\left(70.5^{\circ}, 60^{\circ}, 45.6^{\circ}, 26.1^{\circ}, 0^{\circ}, 26.1^{\circ}, 45.6^{\circ}, 60^{\circ}\right.$, $20.5^{\circ}$ ) and gathers data in four different spectral bands (blue, green, red, and near-infrared) of the solar spectrum. The blue band is at wavelength $443 \mathrm{~nm}$, the green band is at wavelength $555 \mathrm{~nm}$, the red band wavelength $670 \mathrm{~nm}$ and the infrared band is at wavelength $865 \mathrm{~nm}$. MISR acquire images at two different levels of spatial resolution i.e. local and global mode. It gathers data at the local mode at $275 \mathrm{~m}$ pixel size and $1.1 \mathrm{~km}$ at the global mode. For this study, we adopted the Level 2 data set over daily period. Typically, the blue band is to analyze coastal and aerosol studies. The green band is to analyze Bathymetric mapping and estimating peak vegetation. The red band analysis the variable vegetation slopes and the infrared band analysis the biomass content and 

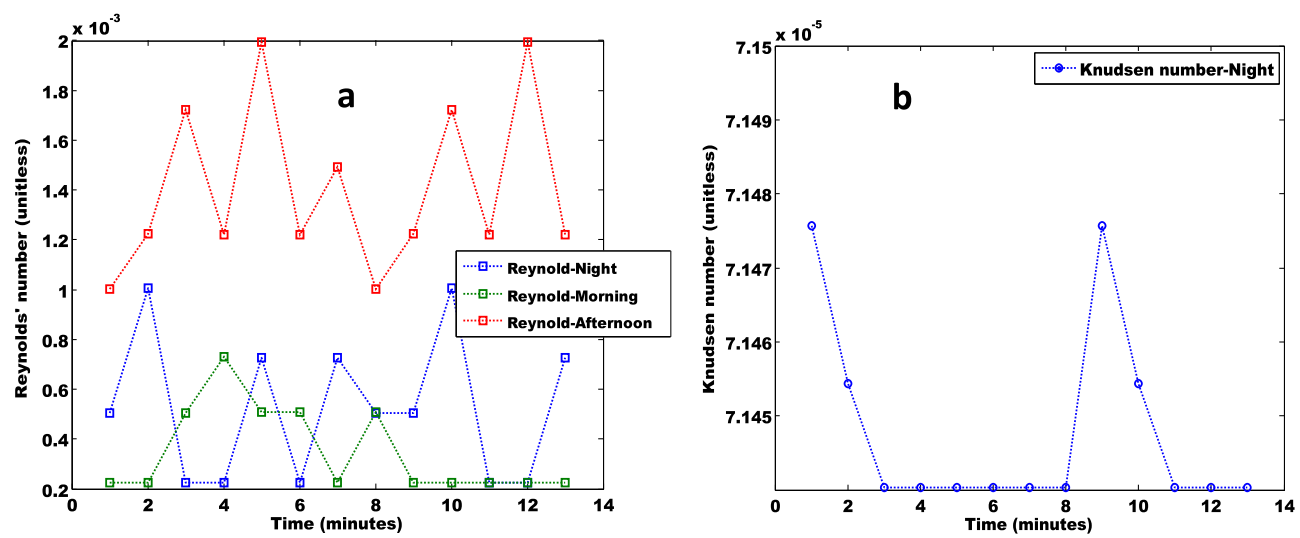

Fig. 3. a: Reynolds number for morning, afternoon and night. b: Knudsen number for night.
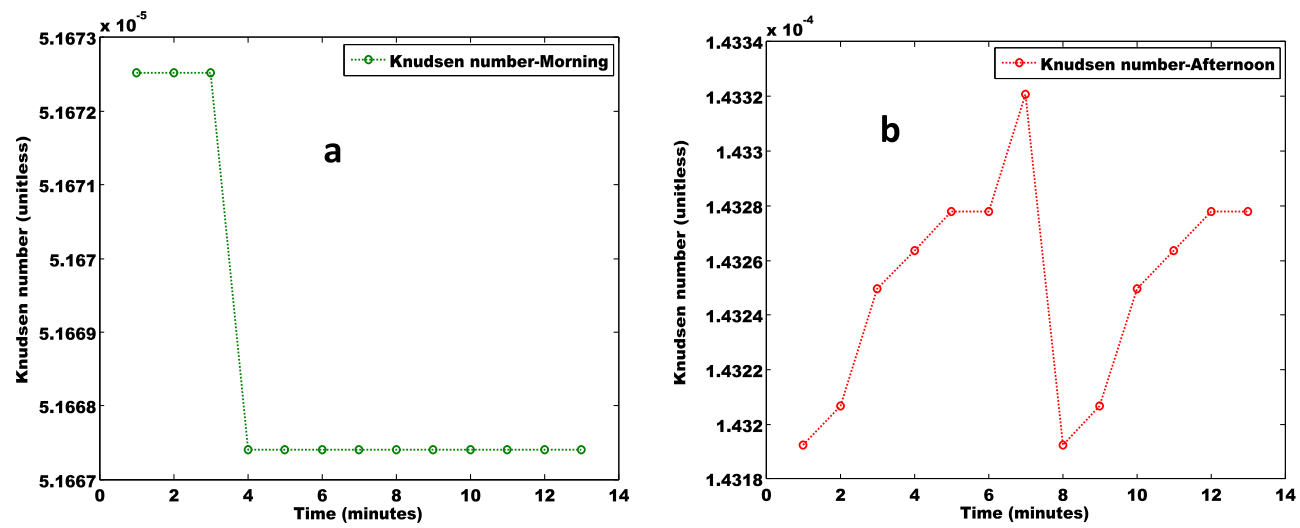

Fig. 4. a: Knudsen number for morning. b: Knudsen number for afternoon.

shorelines. The mono-dispersion and poly-dispersion flows were considered by making $\mathrm{N}=2, A=1 / 2 \delta_{j 3} w_{g}, K_{11}=K_{a}, K_{22}=K_{b}, \psi_{1}=\psi_{a}$, $\psi_{2}=\psi_{b}, D_{1}=D_{a}$, and $D_{2}=D_{b}$. This resulted into two monodispersion flow equations given below

$\left(\frac{\partial K_{a}}{\partial z} \frac{\partial \psi_{a}}{\partial z}+K_{a} \frac{\partial^{2} \psi_{a}}{\partial z^{2}}-A \frac{\partial \psi_{a}}{\partial x}\right)+\frac{\partial \psi_{a}}{\partial t}=\tau D_{a}$

$\left(\frac{\partial K_{b}}{\partial z} \frac{\partial \psi_{b}}{\partial z}+K_{b} \frac{\partial^{2} \psi_{b}}{\partial z^{2}}-A \frac{\partial \psi_{b}}{\partial x}\right)+\frac{\partial \psi_{b}}{\partial t}=\tau D_{b}$

The general term which describes the poly-dispersion flow is given as

$$
\begin{aligned}
& \left(\frac{\partial}{\partial z}\left(K_{a}+K_{b}\right) \frac{\partial}{\partial z}\left(\psi_{a}+\psi_{b}\right)+K_{a} \frac{\partial^{2} \psi_{a}}{\partial z^{2}}+K_{b} \frac{\partial^{2} \psi_{b}}{\partial z^{2}}-A \frac{\partial}{\partial x}\left(\psi_{a}+\psi_{b}\right)\right) \\
& +\frac{\partial}{\partial t}\left(\psi_{a}+\psi_{b}\right)=\left(D_{a}+D_{b}\right)
\end{aligned}
$$

Since the dispersion sources are unpredictable on a larger scale, we assume a nearly uniform dispersion from all sources. This assumption was based on the uniform cloud cover index over one of the locations (Abeokuta) for about thirteen years (Emetere Moses et al., 2015). The mixed state of both the mono-dispersion and poly-dispersion flows is therefore represented in a general term as $m \frac{\partial K}{\partial z} \frac{\partial \psi}{\partial z}+K \frac{\partial^{2} \psi}{\partial z^{2}}-A \frac{\partial \psi}{\partial x}+\frac{\partial \psi}{\partial t}=\tau D$

$\mathrm{m}$ is the number of dispersion sources. For simplification of the above equation, $\eta=\partial K / \partial z$ and $B=A \partial \psi / \partial x+\partial \psi / \partial t-\tau D$, hence when Eq. (25) is wavelength dependent, it becomes

$m \eta \frac{\partial \psi(\lambda, t)}{\partial z}+K \frac{\partial^{2} \psi(\lambda, t)}{\partial z^{2}}+B=0$

Let the initial conditions be $\psi(0)=\alpha, \psi \mid(0)=\beta$. The Laplace transform was applied to solve Eq. (26)

$\psi(\lambda, t)=(m \alpha \lambda-B) \cos m \eta t+\beta \sin m \eta t$

If the term ' $\mathrm{B}$ ' is minimum i.e. $B=0$, then

$A \frac{\partial \psi(\lambda, t)}{\partial x}+\frac{\partial \psi(\lambda, t)}{\partial t}-\tau D=0$

Applying the Hermit polynomial

$\psi(\lambda, t)=e^{2 t \lambda-t^{2}}=e^{\lambda^{2}} \cdot e^{(\lambda-t)^{2}}=\sum_{n=0}^{\infty} H_{n}(\lambda) \frac{t^{n}}{n}$

Let $\lambda-t=u$, then $t=\lambda-u=0$ and $-\partial / \partial t=\partial / \partial u .-\partial / \partial t=\partial / \partial u$ is substituted into Eq. (28) to yield two governing equations i.e.

$\frac{\partial \psi(\lambda)}{\partial x}=\tau(\lambda) D$ 


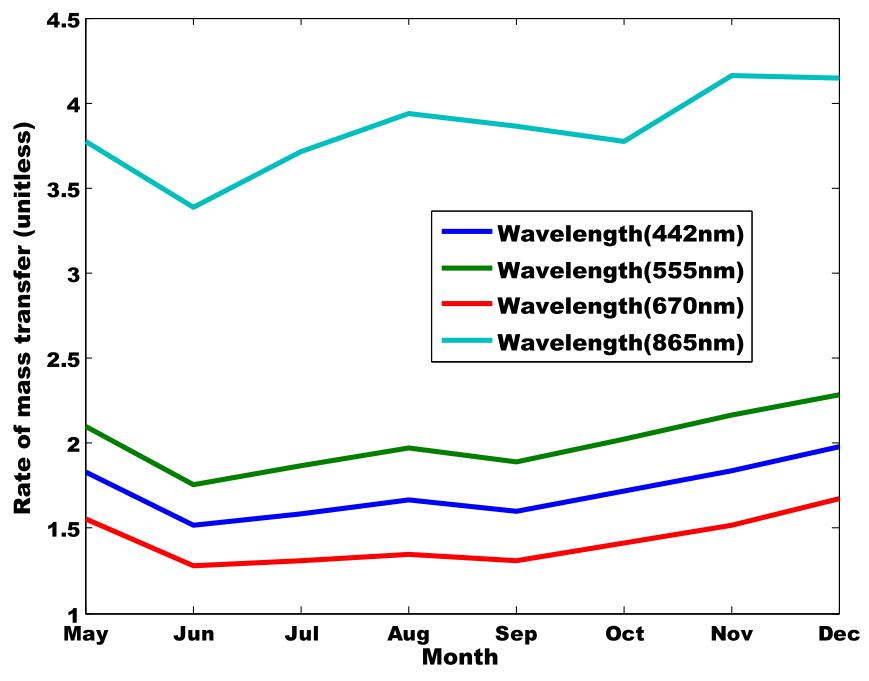

Fig. 5. Mass transfer rate retrieved from the AOD of 2012.

$\frac{\frac{1}{2} \delta_{j 3} w_{g}}{D}-\frac{1}{D}=\tau(\lambda)$

To solve for the turbulence or laminar flow, the initial and boundary conditions for the gravitational settling are

$$
w_{g}=\left\{\begin{array}{cc}
U n<0 & v=0.3 \\
0 \leq U n \leq 1 & v=0.7 \\
1 \leq U n \leq 2 & v=1.36 \\
2 \leq U n \leq 5 & v=2.73 \\
5 \leq U n \leq 10 & v=7.57 \\
10 \leq U n \leq 100 & v=14.8 \\
\text { Un }>100 & v=30.3
\end{array}\right.
$$

Here $\mathrm{v}$ is the settling velocity $(\mathrm{cm} / \mathrm{s})$ and $\delta_{j 3}=1$. Hence the formulation for the aerosol size distribution

$$
A S D=\frac{\gamma}{D}
$$

Here $\gamma$ is assumed to be unity with same unit as D.

\subsection{Numerical simulations of the aerosol size distribution}

In this section, we consider the simulation results of Eqs. (27, 29, 30). The mass transfer rate will be obtained from Eq. (30) and then applied in the Eq. (31). The mass transfer rate in the atmosphere influences the growth and evaporation of the particulates. Hence, we considered 2012 where the mass transfer rate is highest within 2000-2013 (Emetere Moses and Akinyemi, 2013). Unfortunately, the data set that can be retrieved from the AERONET in 2012 for Lagos only captures between May-December (Figs. 5 and 6). It was observed that the mass transfer rate increases almost linearly in the last quarter of the year 2012. The infrared band varies from the blue, red and green bands. However, the point of similarity lies within the drop of the mass transfer rate in June and a gradual rise till August for all bands. From literatures, rainfall or precipitation scavenging reduces the atmospheric aerosols content (Kyle, 1991; Gwen and Cederwall, 2004). This effect leads to a reduced aerosols scattering and improved atmospheric visibility. Despite the highest rainfall and hydrological disaster (Emetere Moses, 2014) recorded in 2012, a negligible effect on the mass transfer rate was noticed (Fig. 5) as a result of the wind pattern peculiar to Lagos (Sanusi and Abisoye, 2011).

The comparative analysis of the known and proposed models for aerosol size distribution shown in Fig. 6a and b validates Eq. (31). The trending of both models was perfect though its magnitude varies. This further agrees that the errors had been perfectly eliminated using the aerosol dispersion model. The novelty of this paper is the parameterization of bands of either a satellite or ground sensor to individually determine the aerosol size distribution over an area per time. Since, the kinetic mass transfer rate has direct influence over gaseous and condensed phases of aerosols, the aerosol size distribution aerosol is expected to display the increase or decrease in volatility and bulk diffusivity. The Eck's model shown in Eq. (2) shows an aerosol size range of $0.1-3.6 \mu \mathrm{m}$ between May and December while the proposed model showed an aerosol size range of $0.1-0.8 \mu \mathrm{m}$ between May and December. These results further confirmed the shortcoming of the Eck's model - it expands the fundamental errors of the protocols. Hence, the proposed model shows the actual aerosol size distribution over Lagos with the major peaks recorded in June and September of 2012. The twelve months aerosol size distribution in 2013 shows four peaks at January, April, July and September (Fig. 7). The significant peak shift of the mid-year aerosol size distribution of 2012 and 2013 (June to July) is worth noting.

A complete one year data was considered for 2013 (Fig. 7a and b). Both models gave the same trending for each band. However, the unified number for this result increased i.e. Un $=1.36$. This shows that the turbulence flow determines the ASD pattern or magnitude. May to October had the highest ASD build-up.
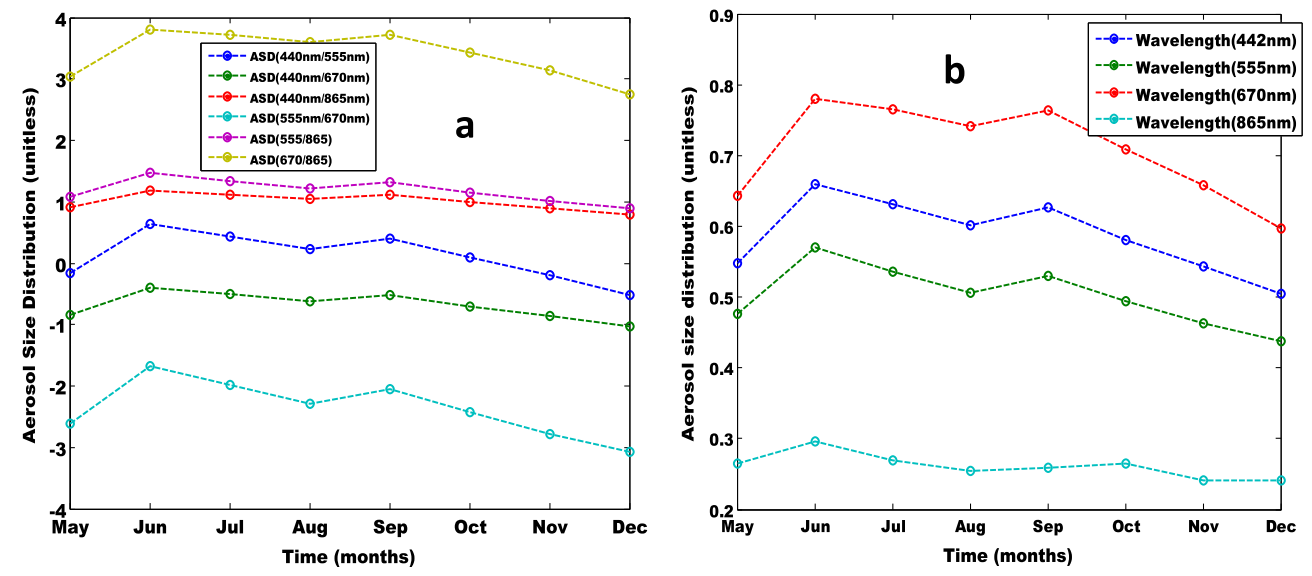

Fig. 6. a: Aerosol size distribution via Eq. (2) for 2012. b: Aerosol size distribution of the proposed model for 2012. 

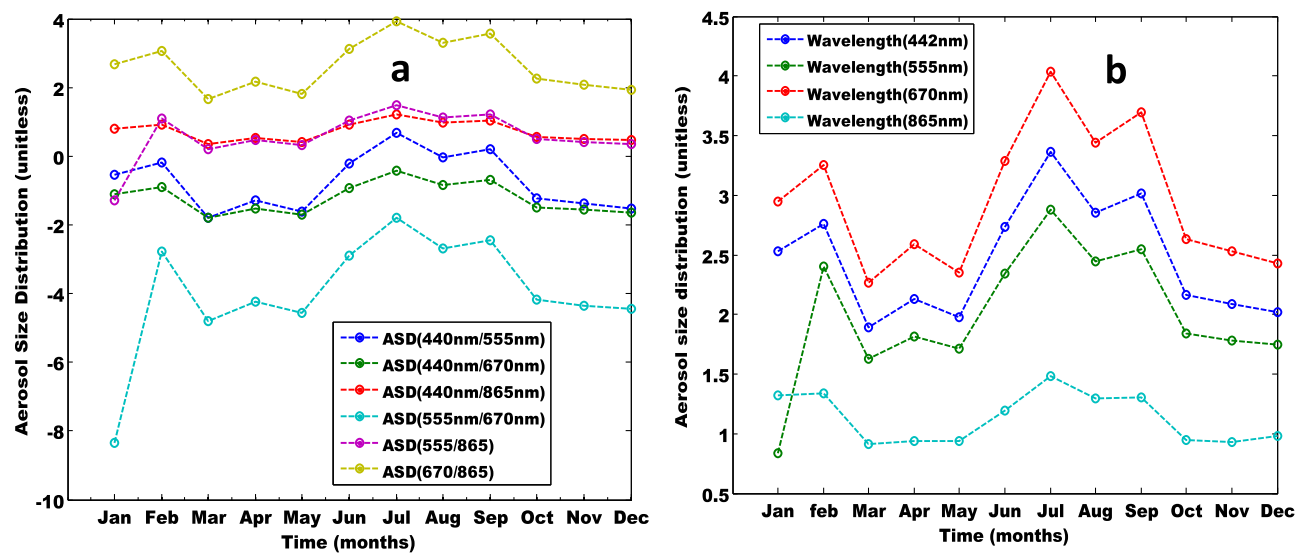

Fig. 7. a: Aerosol size distribution via Eq. (2) for 2013. b: Aerosol size distribution of the proposed model for 2013.

\subsection{Discussion}

A retrieval model which affords vital information from independent spectral aerosol optical depth (that predicts established theories from a comprehensive model) was achieved. The adoption of the dispersion plume model in Eqs. (8-11) to determine vital aerosol size properties of the coastal urban region is unique (as illustrated in Fig. 8). Hence there lies the possibility of multiple refractive index which varies with respect to the number of dispersion source, volume of pollutant dispersed, the decay or aging constant, mixing of the Tropospheric column e.t.c. Hence, Eq. (12) may be used to assess the refractive indexes which we propose as the atmospheric constant over an area. This process can be achieved by using remotely sensed data for at least ten years (Omotosho et al., 2015). The minute analysis shows that the unified number captured both the westerly and easterly air masses which determine the aerosol loading or transport over the urban area (Figs. 1b and 2b). The shape, size and magnitude defined in Fig. 2a affirm the existence of at least three modes of aerosol particles i.e. coarse mode, nucleation mode, aitken mode and accumulation mode. For example, when $\mathrm{Un}=0.1$, it is most likely to be the presence of accumulation mode, $\mathrm{Un} \leq 0.3$, the aitken mode is likely present, Un $\leq 0.5$, the nucleation mode is likely present, Un $\geq 0.9$, the coarse mode is likely present. It shows that in the afternoon,

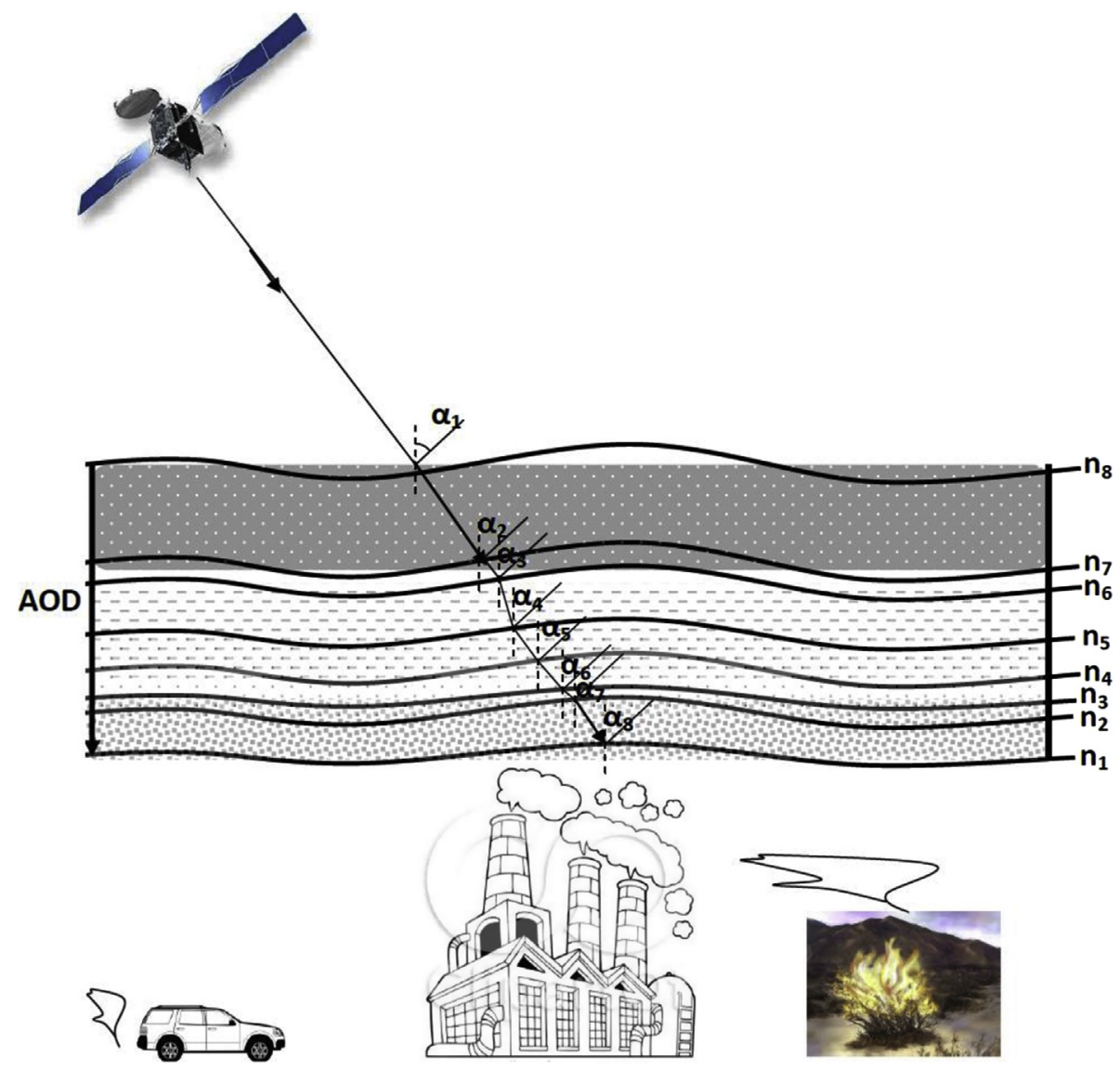

Fig. 8. Illustration of the retrieval model. 
more of the coarse mode and little of nucleation can be observed in Fig. 2b. This may be as a result of an increased traffic movement, industrial activities, biomass burning. However, the transport of the aerosol and the determination of the number size distribution may be complex due to vertical mixing, nucleation, coagulation, plume dilution and condensational growth (Turco and Fangqun, 1999; Wu et al., 2002). This difficulty was solved by our model in Eq. (27) which is a refinement of Eq. (12). The vital aerosol property i.e. plume dilution $(\eta=\partial K / \partial z)$ was included to monitor aerosol number size distribution at whatever layer ' $m$ ' when performing a more systematic experimentation. In the night, the minute analysis showed the presence of three modes i.e. nucleation, aitken and accumulation mode. Fig. $2 \mathrm{~b}$ shows that the nucleation mode and accumulation mode was more pronounced at the peaks and trough. The morning showed the presence of three modes with majority at the accumulation mode. The seasonal analysis showed the features of the mass transfer rate. The mass transfer rate is a vital property which defines transportation and distribution of the aerosol particles. The highest mass transfer during the raining season was noticed in August (Fig. 5). The 'August break' fosters mass transfer rate via vertical mixing and plume dilution. The presence of the easterly wind can be seen from September to December. What does this experience portend for the aerosol size distribution? Fig. 7b, showed that size distribution lower from October to January. Hussein et al. (2004) explained that this occurrence was due to lower total number concentration. This may be due to massive coagulation and nucleation which occurred from May to July. The magnitude of the coagulation and nucleation during May to July determine the extensive effect to preceding months. For example, In Helsinki, the effect extended to February (Hussein et al., 2004) while the effect in Lagos (Fig. 7b) extended to January. January to March (JFM) and August to October (ASO) showed same pattern. However, the difference between both seasons is the modal structure which may be due to the presence of long term aerosol. If this assumption is true, this means that about $15 \%$ of the long term aerosol extends to the ASO.

\section{Conclusions}

The size characteristics of atmospheric aerosol were examined using two years ground observations and a mathematically derived dispersion model. The modified fixed sectional technique was adopted by successfully introducing dynamic constants which was obtained from the unified number. The minute analysis of the wind speed over Lagos shows that the unified number captured both the westerly and easterly air masses which determine the aerosol loading or transportation over the urban area. From Fig. 2a, we learn that at least three modes of aerosol particles i.e. coarse mode, nucleation mode, aitken mode and accumulation mode exists in Lagos. The coarse mode and little of nucleation can be observed in the afternoon. From the literatures, we learn that biomasses burning are common activity during October to February. Therefore, the aerosol concentration in the atmosphere ought to be high. This assumption has been nullified by Hussein et al. (2004) who affirmed that the total number of concentration is low. In this paper, we propose that the low total number of concentration between October and February is due to an extensive effect of larger activity of agglomeration, coagulation and nucleation during May to July. However, the trend noticed in January to March (JFM) and August to October (ASO) shows a 15\% retention of long term aerosol extension generated between October and February. The minute analysis from the Davis weather station shows that the unified number captured both the westerly and easterly air masses which determine the aerosol loading or transportation over the urban area.

\section{Acknowledgment}

The authors appreciate NASA for allowing the use of the satellite data set which can be obtained from http://gdata1.sci.gsfc.nasa.gov/ daac-bin/G3/download. The authors acknowledge the partial supports of Covenant University for the Davis weather station data set which can be obtained by contacting hodphysics@ covenantuniversity.edu.ng. The authors express their profound gratitude to the reviewers for the constructive review of this paper.

\section{References}

Aloyan, A.E., Arutyunyan, V.O., Yermakov, A.N., Zagaynov, V.A., Mensink, C., De Ridder, K., Van de Vel, K., Deutsch, F., 2012. Modeling the Regional Dynamics of Gaseous Admixtures and Aerosols in the Areas of Lake Baikal (Russia) and Antwerp (Belgium). Aerosol Air Qual. Res. 12, 707-721.

Che, H., Xia, X., Zhu, J., Li, Z., Dubovik, O., Holben, B., Goloub, P., Chen, H., Estelles, V., Cuevas-Agulló, E., Blarel, L., Wang, H., Zhao, H., Zhang, X., Wang, Y., Sun, J., Tao, R., Zhang, X., Shi, G., 2014. Column aerosol optical properties and aerosol radiative forcing during a serious haze-fog month over North China Plain in 2013 based on ground-based sunphotometer measurements. Atmos. Chem. Phys. 14, 2125-2138.

Eck, T.F., Holben, B.N., Reid, J.S., Dubovik, O., Smirnov, A., O'Neill, N.T., Slutsker, I., Kinne, S., 1999. Wavelength dependence of the optical depth of biomass burning, urban, and desert dust aerosols. J. Geophys. Res. 104, 333-349.

Emetere Moses, E., 2013. Modeling of particulate radionuclide dispersion and deposition from a cement factory. Ann. Environ. Sci. 7 (6), 71-77.

Emetere Moses, E., 2014a. Theoretical forecast of the health implications of citing nuclear power plant in Nigeria. J. Nucl. Part. Phys. 4 (3), 87-93.

Emetere Moses, E., 2014b. Forecasting hydrological disaster using environmental thermographic modeling. Adv. Meteorol. 2014, 783718

Emetere Moses, E., Akinyemi, M.L., 2013. Modeling of generic air pollution dispersion analysis from cement factory. Analele Univ. Din. Oradea-Seria Geogr. 231123-628, 181-189.

Emetere Moses, E., Akinyemi, M.L., Akin-Ojo, O., 2015. Aerosol optical depth trends over different regions of Nigeria: thirteen years analysis. Mod. Appl. Sci. 9 (9), 267-279.

Giglio, L., Randerson, J.T., van der Werf, G.R., Kasibhatla, P.S., Collatz, G.J., Morton, D.C., DeFries, R.S., 2010. Assessing variability and long-term trends in burned area by merging multiple satellite fire products. Biogeosciences 7 , 1171-1186.

He, Q., Li, C., Geng, F., Yang, H., Li, P., Li, T., Liu, D., Pei, Z., 2012. Aerosol optical properties retrieved from sun photometer measurements over Shanghai, China. J. Geophys. Res. 117, D16204.

Hussein, T., Puustinen, A., Aalto, P.P., Makela, J.M., Hameri, K., Kulmala, M., 2004. Urban aerosol number size distributions. Atmos. Chem. Phys. 4, 391-411.

Kaskaoutis, D.G., Kalapureddy, M.C.R., Moorthy, K.K., Devara, P.C.S., Nastos, P.T., Kosmopoulos, P.G., Kambezidis, H.D., 2010. Heterogeneity in pre-monsoon aerosol types over the Arabian Sea deduced from ship-borne measurements of spectral AODs. Atmos. Chem. Phys. 10, 4893-4908.

Kumar, D., Kumar, A., Kumar, V., Kumar, J., Ravi, P.M., 2013. Study of atmospheric stagnation, recirculation and ventilation potential at Narora Atomic Power Station NPP site. Environ. Monit. Assess. 185 (4), 2887-2894.

Kumierczyk-Michulec, Jolanta, 1993. The aerosol optical thickness of the atmosphere over the Norwegian Sea obtained from different experimental data. Oceanologia 34, 27-37.

Kyle, Thomas G., 1991. Atmospheric Transmission, Emission, and Scattering. Pergamon Press, Oxford, New York, p. 56.

Lehtinen, K.E.J., Kulmala, M., 2003. A model for particle formation and growth in the atmosphere with molecular resolution in size. Atmos. Chem. Phys. 3, 251-257.

Liou, K.N., 2002. An Introduction to Atmospherics Radiation. Academic Press, London, UK, p. 33.

Liu, Y., Wang, Z., Wang, J., Ferrare, R., Newsom, R., Welton, E., 2011. The effect of aerosol vertical profiles on satellite-estimated surface particle sulfate concentrations. Remote Sens. Environ. 115 (2), 508-513.

Lohmann, U., Feichter, J., Penner, J., Leaitch, R., 2000. Indirect effect of sulfate and carbonaceous aerosols: a mechanistic treatment. J. Geophys. Res. 105 (12), 193-206.

Loosmore, Gwen A., Cederwall, Richard T., 2004. Precipitation scavenging of atmospheric aerosols for emergency response applications: testing an updated model with new real-time data. Atmos. Environ. 38, 993-1003.

Nicholson Sharon, E., 2013. The west African Sahel: a review of recent studies on the rainfall regime and its interannual variability. ISRN Meteorol. 2013, 453521.

Omotosho, T.V., Emetere, M.E., Arase, O.S., 2015. Mathematical projections of air pollutants effects over Niger Delta region using remotely sensed satellite data. Int. J. Appl. Environ. Sci. 10 (2), 651-664.

Onyeuwaoma, Nnaemeka Dominic, Nwofor, Okechukwu Kelechi, Chineke, Theo Chidiezie, Eguaroje, Ezekiel Onoshi, Dike, Victor Nnamdi, 2015. Implications of MODIS impression of aerosol loading over urban and rural settlements in Nigeria: possible links to energy consumption patterns in the country. Atmos. Pollut. Res. 6 (1), 484-494. 
Rajeev, K., Ramanathan, V., Meywerk, J., 2000. Regional aerosol distribution and its long-range transport over the Indian Ocean. J. Geophys. Res. 105 (2), 2029-2043.

Sanusi, Y.K., Abisoye, S.G., 2011. Estimation of wind energy potential in Southwestern Nigeria. Pac. J. Sci. Technol. 12 (2), 160-166.

Schotland, R.M., Lea, T.K., 1986. Bias in a solar constant determination by the Langley method due to structured atmospheric aerosol. Appl. Opt. 25, 2486.

Schuster, G.L., Dubovik, O., Holben, B.N., 2006a. Angstrom exponent and bimodal aerosol size distributions. J. Geophys. Res. 111. D07207, 1-13.

Schuster, G.L., Dubovik, O., Holben, B.N., 2006b. Angstrom exponent and bimodal aerosol size distributions. J. Geophys. Res. 111, D07207.

Sharma, N.L., Kuniyal, J.C., Singh, M., Sharma, M., Guleria, R.P., 2011. Characteristics of aerosol optical depth and Ångstrom parameters over Mohal in the Kullu valley of northwest Himalayan region, India. Acta Geophys. 59 (2), 334-360.

Sicard, M., D'Amico, G., Comerón, A., Mona, L., Alados-Arboledas, L., Amodeo, A., Baars, H., Belegante, L., Binietoglou, I., Bravo-Aranda, J.A., Fernández, A.J. Fréville, P., García-Vizcaíno, D., Giunta, A., Granados-Muñoz, M.J., GuerreroRascado, J.L., Hadjimitsis, D., Haefele, A., Hervo, M., Iarlori, M., Kokkalis, P., Lange, D., Mamouri, R.E., Mattis, I., Molero, F., Montoux, N., Muñoz, A., Muñoz Porcar, C. Navas-Guzmán, F. Nicolae, D. Nisantzi, A., Papagiannopoulos, N. Papayannis, A., Pereira, S., Preißler, J., Pujadas, M., Rizi, V., Rocadenbosch, F., Sellegri, K., Simeonov, V., Tsaknakis, G., Wagner, F., Pappalardo, G., 2015. EARLINET: potential operationality of a research network. Atmos. Meas. Tech. Discuss. 8, 6599-6659.

Soukharev, B.E., Hood, L.L., 2006. Solar cycle variation of stratospheric ozone: Multiple regression analysis of long-term satellite data sets and comparisons with models. J. Geophys. Res. 111, 1-18, D20314.

Turco, R.P., Fangqun, Y., 1999. Particle size distributions in an expanding plume undergoing simultaneous coagulation and condensation. J. Geophys. Res. 104,
$19227-19241$.

Vakkari, V., Kerminen, Veli-Matti, Beukes, Johan Paul, Tiitta, Petri, van Zyl, Pieter G. Josipovic, Miroslav, Venter, Andrew D., Jaars, Kerneels, Worsnop, Douglas R., Kulmala, Markku, Laakso, Lauri, 2014. Rapid changes in biomass burning aerosols by atmospheric oxidation. Geophys. Res. Lett. 41, 2644-2651.

von Salzen, K., Leighton, H.G., Ariya, P.A., Barrie, L.A., Gong, S.L., Blanchet, J.P., Spacek, L., Lohmann, U., Kleinman, L.I., 2000. Sensitivity of sulphate aerosol size distributions and CCN concentrations over North America to SOx emissions and H2O2 concentrations. J. Geophys. Res. 105, 9741-9765.

Wang, Y., Sartelet, K.N., Bocquet, M., Chazette, P., Sicard, M., D'Amico, G., Léon, J.F., Alados-Arboledas, L., Amodeo, A., Augustin, P., Bach, J., Belegante, L. Binietoglou, I., Bush, X., Comerón, A., Delbarre, H., García-Vízcaino, D., GuerreroRascado, J.L. Hervo, M. Jarlori, M. Kokkalis, P. Lange, D. Molero, F, Montoux, N., Muñoz, A., Muñoz, C., Nicolae, D., Papayannis, A., Pappalardo, G., Preissler, J., Rizi, V., Rocadenbosch, F., Sellegri, K., Wagner, F., Dulac, F., 2014 Assimilation of lidar signals: application to aerosol forecasting in the western Mediterranean basin. Atmos. Chem. Phys. 14, 12031-12053.

Wang, L.C., Gong, W., Xia, X.A., Zhu, J., Li, J., Zhu, Z.M., 2015. Long-term observations of aerosol optical properties at Wuhan, an urban site in Central China. Atmos. Environ. 101, 94-102.

Welton, E.J., Kenneth, J.V., Patricia, K.Q., Piotr, J.F., Krzyszt, M., James, E.J., 2002 Measurements of aerosol vertical profiles and optical properties during INDOEX 1999 using micropulse lidars. J. Geophys. Res. 107 (D1), 8019.

Wu, Y., Hao, J., Fu, L., Wang, Z., Tang, U., 2002. Vertical and horizontal profiles of airborne particulate matter near major roads in Macao, China. Atmos. Environ. 36, 4907-4918.

Zhang, T., Xu, Ning, Guo, L., YH, Yong, B., 2014. A global atmospheric contaminant transport model based on 3D advection-diffusion equation. J. Clean Energy Technol. 2 (1), 43-47. 